\title{
Evaluation of the ultimate drying shrinkage of cement-based mortars with poroelastic models
}

\author{
Carmelo Di Bella $\cdot$ Mateusz Wyrzykowski - Pietro Lura
}

Received: 1 December 2015/Accepted: 9 April 2016

(C) RILEM 2016

\begin{abstract}
In this study, the ultimate drying shrinkage of three different cement-based mortars, with and without supplementary cementitious materials, was investigated. Experimental results were compared to the predicted ultimate shrinkage values obtained by three different poroelastic approaches. The different poroelastic models predict similar ultimate shrinkage as a function of the relative humidity especially in the higher range (above about $50 \% \mathrm{RH}$ ). The experimentally-measured ultimate drying shrinkage is predicted reasonably well by the different models, with the highest deviations observed for the slag-containing mortars. The most important parameters that influence the predictions are discussed and their effect is quantified. The uncertainty of the shrinkage predictions resulting from error propagation of the input parameters is estimated using a parametric bootstrap technique.
\end{abstract}

Keywords Poroelastic modeling - Drying shrinkage $\cdot$ Sorption isotherms $\cdot$ Mortar $\cdot$ Humidity

C. Di Bella $(\bowtie) \cdot$ M. Wyrzykowski · P. Lura Empa, Swiss Federal Laboratories for Materials Testing and Research, Dübendorf, Switzerland

e-mail: carmelo.dibella@empa.ch

C. Di Bella $\cdot$ P. Lura

ETH Zurich, Swiss Federal Institute of Technology

Zurich, Zurich, Switzerland

\section{Introduction}

During their service life, concrete structures undergo several types of volume changes as a result of the material's response to internal chemical processes and external and/or environmental load. Drying of moisture to the environment leads to drying shrinkage (a volume reduction) resulting from the drop in the internal relative humidity $(\mathrm{RH})$ in the pores of the concrete. If the volume reduction due to shrinkage is hindered by internal or external restraint $[1,2]$, residual tensile stresses build up that may lead to warping and/or micro- and macro-cracking [3, 4]. Eventually, damaged concrete structures experience reduced durability and service life, which has a tremendous economic impact. Prediction of the volume changes of concrete structures at the design stage remains one of the most efficient and economical strategies to account for the volumetric instability due to drying and enables further measures for minimizing stresses development and possible cracking.

During the past years, several shrinkage models have been suggested to estimate the magnitude and the rate of the time-dependent deformations. They can be divided into two main categories: phenomenological models and mechanistic models.

Belonging to the first group, the ACI 209R model [5], the Eurocode 2 [6], the B3 model [7], the CEB-FIP model [8] or the GL 2000 [9] are all empirical models obtained through best-fit analysis of experimental data. Several drawbacks are usually associated with 
these models, mostly due to the large uncertainty in predicting the shrinkage and the considerable amount of input parameters that are required [10-12]. Al Manasser and Lam [13] performed a statistical evaluation of four shrinkage models (ACI 209R-92, CEB 90, B3 and GL 2000), concluding that the B3 model and the GL2000 models lead to the best predictions, whereas the ACI 209R-92 model overestimates the short-term shrinkage strains and underestimates the long-term ones [14]. It is possible to improve the shrinkage prediction when short-term measurements (about 1-3 months) are available [10]. Despite some attempts of taking into account shrinkage deformations of structures made with denser concrete [15], autogenous shrinkage or presence of chemical admixtures, [16, 17], the shortcoming of the aforementioned models is based on the excessive amount of data necessary for validation of these models, and their limited applicability to non-standard materials.

Based on the fact that the drying shrinkage of mortar and concrete is driven by the shrinkage of the cement paste and depends on its volume fraction in the composite, other researchers have tried to derive models from the theory of elasticity and composite theory $[11,18,19]$. Nevertheless, while using paste or mortar to finally estimate shrinkage of concrete has the advantage of dealing with less material and smaller samples, such approach would still need long-term measurements, because the shrinkage of the paste is needed as input.

Proper prediction of concrete volume changes requires a fundamental understanding of the mechanisms and of the physical properties involved in the process, to be able to embrace different types of concrete mixtures and applications. To this end, the volume changes of an isotropic porous medium such as concrete can be described by means of poromechanics [20].

Accordingly, in the framework of poroelasticity, in which the solid skeleton of the porous material is considered to behave elastically, the constitutive shrinkage behavior of porous materials can be described knowing the mechanisms causing the volume change, their moisture state and their elastic properties.

Coussy et al. [21] modelled the macroscopic shrinkage of cement paste and concrete on the basis of the thermodynamics of open continua. BaroghelBouny et al. concluded that the model based on capillary stresses was "quite suitable at least for engineering purposes" [22]. On the contrary, Vlahinić et al. stated that "the experimental results of elastic shrinkage during drying of hardened cement paste are consistently greater than predictions" and provided a new constitutive formulation in the effective stress framework, considering the weakening of the solid skeleton upon drying [23]. Similarly, Rougelot et al. included the effects of saturation in the bulk modulus of the matrix [24]. Both studies, [23] and [24], considered a partially saturated porous medium as a saturated material in which desaturated pores are included in the matrix as closed porosity. Such approach leads to the dependence of the compressibility of the porous body upon saturation, assuming that a decrease in the saturation corresponds to a decrease of the bulk modulus of the skeleton.

Bentz et al. [25] investigated the shrinkage behavior of porous Vycor glass using an analytical method based on work by Mackenzie [26] (equivalent to the Biot-Bishop formulation discussed in Sect. 2.2) and obtained good agreement between simulation and experiments only in the upper $\mathrm{RH}$ range (between 94 and $80 \%$ ).

Lura et al. modeled the autogenous shrinkage of cement based pastes using the Biot-Bishop formulation, obtaining good predictions only in the higher $\mathrm{RH}$ range [27]. At lower $\mathrm{RH}$ the underestimation of the measured shrinkage was attributed to the influence of creep and to the pozzolanic reaction of the silica fume. Indeed, in the above-mentioned poroelastic models, the material is treated as porous, isotropic and linear elastic, excluding possible microcracking or creep effects. Grasley and Leung [28] described shrinkage of hardened cement paste including a viscoelastic component making use of solidifying and poroviscoelastic models with intrinsic aging of the calcium-silicate hydrate (CSH).

In this paper, the experimentally-determined drying shrinkage at moisture equilibrium of three mortars is compared with predictions obtained by three different mechanistic models that consider different mechanisms and solid response causing the shrinkage. The three mortars are an Ordinary Portland Cement (OPC) mortar and two additional mortars where $45 \%$ (by volume) of the cement in the paste was replaced by slag and silica fume, respectively.

Three different formulations for description of drying shrinkage were examined. The first one is the 
classical Biot-Bishop [29, 30] poroelastic approach for unsaturated media using the concept of averaged pressure exerted by pore fluids. The second poroelastic approach by Coussy et al. [21], instead of an averaged pressure, takes into account an equivalent pore pressure that includes a term for the surface free energy. Finally, the third approach is a modification of the Biot-Bishop approach that accounts for the weakening of the solid skeleton during drying, as proposed by Vlahinić et al. [23]. These approaches are presented in detail in Sect. 2.2.

One of the key aspects in modeling based on experimentally-determined input data is the assessment of the uncertainty of the model predictions that originates from the combined errors of the input (random) data. This aspect should be addressed with propagation of uncertainty (also referred to as error propagation) [31]. Analytical solutions for propagation of uncertainty can become a very tedious task if the function of the input data is complex, i.e. it involves many parameters that are not independent, like in the case of shrinkage predictions described in Sect. 2. In order to overcome this difficulty, a parametric bootstrapping technique [31] is used here for estimation of uncertainty of drying shrinkage predictions.

\section{Mechanistic drying shrinkage modeling: mechanisms and formulations}

\subsection{Drying shrinkage mechanisms}

Despite the great deal of research in the past decades, several uncertainties remain in describing the mechanisms behind the drying shrinkage of cement based materials [32-34]. Nevertheless, it is generally agreed that more than one mechanism is involved during drying and their effectiveness depends on the water content and on its state within the porous body.

In the literature, drying shrinkage of cement-based materials is considered to be a consequence of changes in disjoining pressure, capillary pressure and surface free energy and combinations thereof, accompanying a decrease of saturation and internal RH, e.g. [27, 28].

According to Derjaguin et al. [35] when the RH increases, the disjoining pressure, $\Pi(\mathrm{Pa})$, can be seen as the force that pushes apart the particles overcoming the van der Waals attractions due increasing adsorption of water in the regions where the full adsorption thickness cannot develop at a given RH, see also [36, 37]. Conversely, when the RH decreases, desorption of water from the hindered adsorption regions leads to a decrease of the disjoining pressure, hence the solid particles are drawn together by the van der Waals attraction forces, resulting in net shrinkage. A comprehensive discussion of disjoining pressure and attractive and repulsive forces in solids-pore water systems can be found in recent work by Setzer [38].

The capillary pressure $p_{\mathrm{c}}$ in the pore water is another mechanism that is usually employed to describe the hygric strains in porous materials [39]. It is related to the formation of water-air menisci in the partially-empty pores, which induce an isotropic compressive stress within the rigid solid skeleton that leads to bulk shrinkage.

It should be noted that the linear momentum conservation between the two populations of water, namely water in hindered adsorption areas and water condensed in capillary pores, in fact requires that the capillary pressure and disjoining pressure are at all times in equilibrium [28]. Changes in pressure exerted by the pore fluids on the skeleton that cause shrinkage, which can be considered to be due either to capillary or disjoining pressure, are related to the internal $\mathrm{RH}$ through the Kelvin-Laplace equation:

$p_{\mathrm{c}}=\Pi=\frac{\rho R T \ln (R H)}{M}$

where $\rho\left(\mathrm{kg} / \mathrm{m}^{3}\right)$ is the density of the pore fluid, assumed as $1000 \mathrm{~kg} / \mathrm{m}^{3}, R$ is the universal gas constant equal to $8.314[\mathrm{~J} /(\mathrm{mol} \mathrm{K})], T(\mathrm{~K})$ is the temperature (in this study, $293.15 \mathrm{~K})$ and $M(\mathrm{~kg} / \mathrm{mol})$ is the molar mass of the pore fluid, assumed equal to that of water $0.01802 \mathrm{~kg} / \mathrm{mol}$, (for a discussion of these parameters, see [40]).

At low RH (about below $40 \%$ ), shrinkage and swelling are believed to be influenced by the surface free energy change due to de-/adsorption of water on the surface of the CSH [36]. The surface energy change is greatest during adsorption of the first monolayer and becomes negligible with increasing amounts of adsorbed water [41]. Conversely, removal of adsorbed water causes shrinkage. It should be emphasized that most concrete structures are not continuously exposed to RH below $40 \%$ and consequently the internal RH rarely reaches such low levels [42]. 


\subsection{Comparison of models}

The deformation of a porous saturated body can be described using the approach developed by Biot [29, 43] and Biot and Willis [44], see also [45-47]:

$\varepsilon_{v}=p\left(\frac{1}{K_{\mathrm{b}}}-\frac{1}{K_{\mathrm{s}}}\right)$

where $K_{\mathrm{b}}(\mathrm{Pa})$ is the drained bulk modulus of the porous body and $K_{\mathrm{s}}(\mathrm{Pa})$ is the bulk modulus of its solid skeleton. According to this approach, in absence of any external loads the volumetric deformations are solely due to changes in pore water pressure $p(\mathrm{~Pa})$.

The extension of this approach to partially-saturated porous materials was developed by Bishop [30], who introduced the concept of two fluids at different pressures ( $p_{\mathrm{w}}$ for water and $p_{\mathrm{g}}$ for gas pressure) occupying the pores. After assuming the volumetric saturation degree with liquid pore water $S_{\mathrm{w}}(-)$ as averaging factor, the average pore pressure in the pores can be expressed as $p=S_{\mathrm{w}} p_{\mathrm{w}}+\left(1-S_{\mathrm{w}}\right) p_{\mathrm{g}}$ [48, 49]. Neglecting the contribution of the gas pressure and further considering that $p_{\mathrm{c}}=p_{\mathrm{g}}-p_{\mathrm{w}}$, the average pore pressure reduces to $p=-S_{\mathrm{w}} p_{\mathrm{c}}$. This leads to the following equation:

$\varepsilon_{\mathrm{v}}=-S_{\mathrm{w}} p_{\mathrm{c}}\left(\frac{1}{K_{\mathrm{b}}}-\frac{1}{K_{\mathrm{s}}}\right)$

where $p_{\mathrm{c}}$ increases due to decrease of $\mathrm{RH}$ (drying), which can be conveniently calculated with the KelvinLaplace Eq. (1), as discussed in the previous section. In this paper, this approach will be called BiotBishop approach.

Coussy et al. provided a formulation to describe the drying shrinkage of cement based materials introducing the concept of equivalent pore pressure $\pi(\mathrm{Pa})$ in place of the averaged pressure into Eq. (2) [50]. The equivalent pore pressure takes into account also the contribution of the interface energy $U(\mathrm{~Pa})$, and was expressed as $\pi=p-U$, where the latter term is [50]:

$U\left(S_{\mathrm{w}}\right)=\int_{S_{\mathrm{w}}}^{1} p_{\mathrm{c}}\left(S_{\mathrm{w}}\right) \mathrm{d} S_{\mathrm{w}}$

and can be calculated knowing the desorption isotherm $p_{\mathrm{c}}(S)$. Finally, the following equation describing volumetric deformations is obtained:
$\varepsilon_{\mathrm{v}}=-\left(S_{\mathrm{w}} p_{\mathrm{c}}+U\right)\left(\frac{1}{K_{\mathrm{b}}}-\frac{1}{K_{\mathrm{s}}}\right)$

A third approach to model the volumetric deformation of unsaturated porous materials was developed by Vlahinić et al. [23]. According to Vlahinić et al., a correct assessment of the extent of weakening of the solid due to desaturation of pores would allow accurate predictions of the volumetric strains. In their approach, the partially-saturated system is thought as fully saturated where the pores are filled with water, while drying affects only the bulk modulus of the effective solid. In other words, the bulk modulus of the solids changes with drying and the relationship is expressed in terms of the degree of water saturation.

In the model by Vlahinić et al. [23], the constitutive formulation for a partially saturated porous medium can be written as:

$\varepsilon_{\mathrm{v}}=-S_{\mathrm{w}} p_{\mathrm{c}}\left(\frac{1}{K_{\mathrm{b}}}-\frac{1}{\bar{K}\left(S_{\mathrm{w}}\right)}\right)$

where $\bar{K}(\mathrm{~Pa})$ is the effective bulk modulus and can be calculated knowing the total porosity $\phi_{0}(-)$ as:

$\bar{K}=K_{\mathrm{s}}-\frac{\left(K_{\mathrm{s}}-K_{\mathrm{b}}\right)\left(1-S_{\mathrm{w}}\right)}{\left(1-S_{\mathrm{w}} \phi_{0}\right)}$

According to the three approaches described above, drying shrinkage can be calculated knowing the driving mechanisms, the degree of saturation, the bulk moduli and the total porosity (notice that the total porosity is necessary only in the last approach by Vlahinić et al. [23]).

For simplicity, in the rest of the paper the three models will be addressed as Biot-Bishop model (Eq. 3), Coussy et al. model (Eq. 5) and Vlahinić et al. model (Eq. 6), respectively.

Except for the porosity, which is used solely in the Vlahinić et al. model, it can be seen that all three formulations are based on the same set of experimental data. As long as experimental determination is rather straightforward for the capillary pressure (environmental condition) and mechanical properties of the porous body $\left(K_{\mathrm{b}}\right)$, for the saturation (and porosity) and for bulk modulus of the solid skeleton, the used input data must be based on assumptions. In order to study this problem, we analyzed the influence of different assumptions regarding input parameters on the final results in detail in Sect. 5. 
2.3 Estimation of uncertainty of model predictions - parametric bootstrapping

Bootstrapping is a statistical method that belongs to a broader class of resampling methods [51]. It consists in simulating a large number of samples (pseudo-data) by resampling from the original data with replacements and drawing conclusions based on the simulated data. Bootstrapping is a powerful and robust technique in particular for assessment of errors of the estimates $[31,51]$.

In the particular case presented here, the function for which the uncertainty propagation is estimated is the shrinkage prediction (according to the three different models), while the input experimental parameters are obtained in the simulations.

For the simulations, a parametric bootstrap technique was used. The generated bootstrap samples (pseudo-data) were obtained by sampling from the assumed underlying distributions. It was assumed that the material properties and the imposed RH all have normal distributions. Therefore, the unknown parameters of the distributions were the mean and the standard deviation. These parameters were assumed to be equal to the corresponding estimates (mean and standard deviation) of the original experimentallydetermined data. The random properties considered were those measured in the experiments for which the variability could be estimated: saturation, static elastic modulus, Poisson ratio and porosity. Additionally, the imposed RH was attributed the standard deviation (never exceeding $0.7 \% \mathrm{RH}$ ) based on the experimental measurements published in [52]. The bulk modulus of the solid skeleton was assumed as a constant value based on literature [53]. For the latter parameter, the effect of the assumed variability was separately estimated.

The procedure of calculating the uncertainty at each considered RH for each considered system can be summarized as follows:

a. for each random property, estimate the parameters of the underlying normal distributions (mean and standard deviation) from the experimental data;

b. for each random property, draw a sample of the same size as the original data from the corresponding normal distributions;

c. calculate the average of the simulated data for each of the parameters; d. calculate the shrinkage according to the models described in Sect. 2.2;

e. Repeat steps b-d 9999 times;

f. from the vector of the calculated shrinkage values (calculated from 9999 generated data sets plus 1 original dataset) determine the 2.5 and $97.5 \%$ quantiles;

g. use the determined quantiles as bootstrap $95 \%$ CI.

\section{Materials and experimental procedure}

\subsection{Materials}

Three mortar mixtures were prepared: one containing OPC as binder (with partial replacement by quartz powder, see later) and two in which $45 \%$ by volume of the cement was replaced by slag and silica fume, respectively. The cement used is a CEM I $52.5 \mathrm{~N}$ with density $3130 \mathrm{~kg} / \mathrm{m}^{3}$; the slag had a density of $2920 \mathrm{~kg} /$ $\mathrm{m}^{3}$, while the silica fume $2340 \mathrm{~kg} / \mathrm{m}^{3}$. X-ray diffraction revealed the following mineralogical composition of the cement (by mass) $61.2 \% \mathrm{C}_{3} \mathrm{~S}, 16.2 \% \mathrm{C}_{2} \mathrm{~S}, 6.6 \%$ $\mathrm{C}_{3} \mathrm{~A}, 10.5 \% \mathrm{C}_{4} \mathrm{AF}$ and $1.8 \% \mathrm{CaSO}_{4}$. The oxide composition of the OPC and SCM is shown in Table 1. The water-to-binder ratio $(\mathrm{w} / \mathrm{b})$ was maintained constant by volume in the different mortars and equal to 1.6, which corresponds to the following $\mathrm{w} / \mathrm{b}$ by mass: $0.52,0.54$ and 0.57 for the OPC, slag and silica fume systems, respectively.

The three mortar mixtures were prepared keeping the amount of sand constant and equal to $50 \%$ of the total volume. The sand had density of $2650 \mathrm{~kg} / \mathrm{m}^{3}$, median grain size (D50) $312 \mu \mathrm{m}$, maximum grain size $650 \mu \mathrm{m}$ and water absorption of $0.2 \%$ by mass.

Table 2 shows the mixture proportions used for the three systems: the aggregate, the binder and the water content are kept constant by volume.

It should be noted that the mortars contained small portions of quartz filler designed to replace the portion of unreacted binder at the equivalent age of 91 days. Replacement of the otherwise unreacted binder at the stage of mixing with unreactive quartz powder enables studying static systems whose microstructures do not evolve over time and with testing. More details about this method can be found elsewhere [54, 55]. The replacement of unreacted binder with quartz can be done at any age. This enables studying early-age 
Table 1 Chemical composition of the materials used (mass\%)

\begin{tabular}{llrllllllll}
\hline & $\mathrm{SiO}_{2}$ & $\mathrm{Al}_{2} \mathrm{O}_{3}$ & $\mathrm{Fe}_{2} \mathrm{O}_{3}$ & $\mathrm{CaO}$ & $\mathrm{MgO}$ & $\mathrm{K}_{2} \mathrm{O}$ & $\mathrm{Na}_{2} \mathrm{O}$ & $\mathrm{SO}_{3}$ & $\mathrm{TiO}_{2}$ & $\mathrm{P}_{2} \mathrm{O}_{5}$ \\
\hline CEM I & 20.10 & 5.02 & 3.14 & 64.48 & 0.99 & 0.87 & 0.17 & 3.33 & 0.23 & 0.33 \\
Slag & 35.82 & 11.16 & 0.27 & 42.29 & 8.31 & 0.34 & 0.17 & 3.33 & 0.23 & 0.01 \\
Silica fume & 91.4 & 0.47 & 0.28 & 0.06 & 0.05 & 0.03 & 0.04 & 0.05 & 0.05 & 0.36 \\
\hline
\end{tabular}

Table 2 Mixture proportions of the tested mortars by mass $\left(\mathrm{kg} / \mathrm{m}^{3}\right)$

\begin{tabular}{llll}
\hline & OPC & Slag & Silica fume \\
\hline Cement & 528 & 313 & 312 \\
Slag & - & 156 & - \\
Silica fume & - & - & 97 \\
Water & 306 & 306 & 306 \\
Sand & 1331 & 1331 & 1331 \\
Quartz & 60 & 101 & 132 \\
\hline
\end{tabular}

properties such as transport properties as well as shrinkage and creep while decoupling the effects of hydration. It should be further noted that fine cement and ground slag were used to speed up the hydration process and obtain unchanging microstructures during measurements of drying shrinkage.

\subsection{Mixing and experimental procedure}

The mortars were mixed in a 5-1 Hobart mixer in accordance with the standard testing method EN 1961. The water was poured into the bowl containing the dry cementitious mixture while mixing at low speed for $30 \mathrm{~s}$. During mixing, the sand was added within a time window of $30 \mathrm{~s}$, followed by additional $30 \mathrm{~s}$ mixing at higher speed. After $90 \mathrm{~s}$ rest, the mortar was again mixed for a final $60 \mathrm{~s}$ at high speed.

After mixing, the mortar was poured into steel molds to form the $150 \times 40 \times 6 \mathrm{~mm}^{3}$ samples. The samples were cast in two layers of about $3 \mathrm{~mm}$ each on a vibrating table. The ends were provided with cast-in gauges able to accommodate the tip of a length comparator to enable shrinkage measurements (Fig. 1).

After casting, the specimens were covered with a plastic sheet and kept in an environmental chamber for approximately $48 \mathrm{~h}$ at $20{ }^{\circ} \mathrm{C}$ and $100 \% \mathrm{RH}$. After

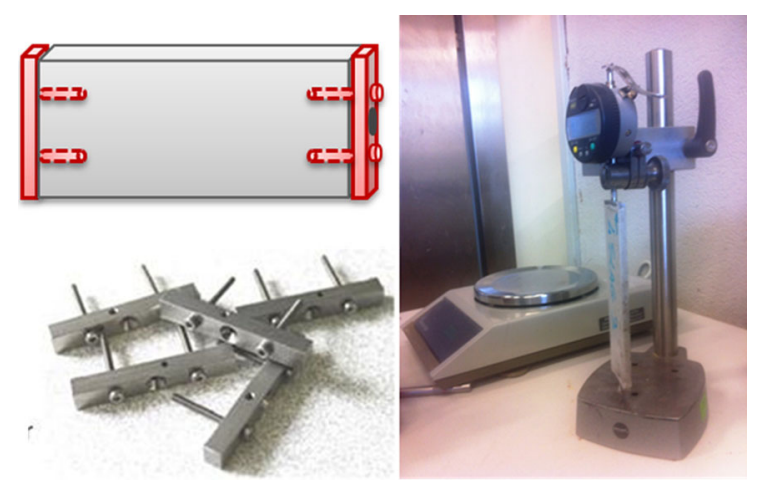

Fig. 1 Schematic representation of the thin mortar samples, customized gauge studs used to accommodate the comparator tip and setup to measure the length and mass change of the mortar samples

demolding, the mortar samples were wrapped in wet towels and sealed in plastic bags to avoid drying and limit carbonation. They were then cured for 91 days in an environmental chamber at $20^{\circ} \mathrm{C}$ and $100 \% \mathrm{RH}$.

At the end of the curing period, the samples were placed in desiccators filled with nitrogen gas (to avoid carbonation) and they were subjected to step-wise RH decrease, with RH controlled by saturated salt solutions Once the samples reached moisture equilibrium at each RH step, they were moved to the next (lower) $\mathrm{RH}$ level. Equilibrium at each RH step was assumed to be reached once the change in mass between two consecutive measurements was smaller than $0.1 \%$ over a period of 2 weeks. It should be noted that no further shrinkage was noticed on the samples once mass equilibrium was reached at the different $\mathrm{RH}$ levels. Small RH steps were used in this study to minimize moisture gradients within the sample, reducing the risk of cracking due to differential shrinkage and self-restraint [56]. In addition, the reduced thickness used in this study allowed reaching equilibrium faster. Three samples were measured for every mortar type. 


\section{Material properties used as input for shrinkage models}

Before proceeding with the comparison between the drying shrinkage experimental results and the predictions according to the different models, in this section the material properties needed as input for the models, i.e. the saturation degree, the bulk moduli and the total porosity, are first discussed.

\subsection{Saturation degree and porosity}

The equilibrium moisture properties of porous materials such as cement-based materials can be understood, quantified and predicted by sorption isotherms (desorption and adsorption), which reflect microstructural features such as total porosity, pore size distribution and degree of connectivity as well as the liquid properties [22, 57, 58]. In this study, desorption isotherms were obtained from the mass-loss measurements carried out on the same thin mortar samples used to measure the shrinkage at equilibrium. The mass change was monitored at different RH steps (97.6, 94.6, 85.1, 75.5, 54.4, and 33.1\%) obtained with saturated salt solutions at $20 \pm 0.3{ }^{\circ} \mathrm{C}$. Once equilibrium was reached, the samples were moved to the following RH step.

Since the saturation degree was calculated as the ratio of the mass of water in the sample to the mass of water in the sample at full saturation (virgin state at the beginning of the tests), an important point was the determination of the reference dry state. For this purpose, companion samples were dried in the oven, using two different temperatures: 50 or $105{ }^{\circ} \mathrm{C}$. In Fig. 2, the saturation degree results of the three mortar mixtures as a function of the $\mathrm{RH}$ are shown as obtained with two different drying regimes $\left(50\right.$ and $\left.105{ }^{\circ} \mathrm{C}\right)$ used to determine the reference dry mass of the samples. For both drying temperatures, a very small scatter between triplicate samples within each system was obtained, with standard deviation not exceeding 0.01 .

Porosity is understood here as a water-accessible porosity, i.e., it was determined based on the initial mass of water in the sample, obtained by referencing a sample mass to its dry mass, the latter obtained as for the saturation degree using two different temperatures: 50 and $105^{\circ} \mathrm{C}$. Sample volume was determined based on Archimedes' principle by weighing the saturated

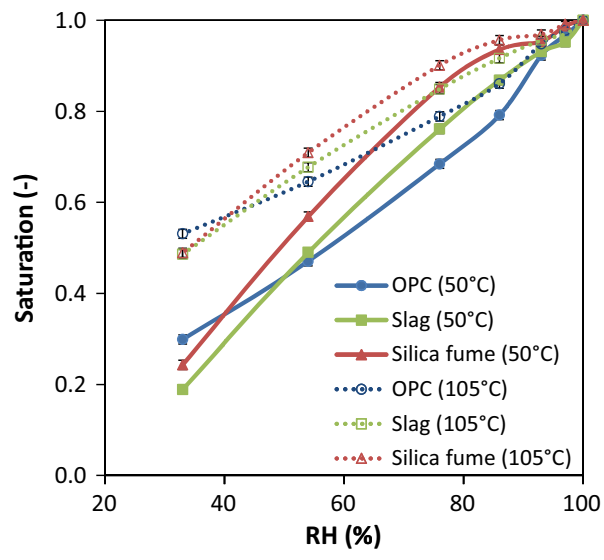

Fig. 2 Saturation degree as a function of the relative humidity for the three mortars determined by using dry reference mass after drying at $50{ }^{\circ} \mathrm{C}$ and at $105{ }^{\circ} \mathrm{C}$. Error bars (not exceeding 0.01 ) represent standard deviation from the three samples for each dataset

samples in air and after immersion in water. The results are presented in Table 3.

\subsection{Bulk moduli}

The bulk modulus of the porous solid $K_{\mathrm{b}}$ was calculated from the combination of the static elastic modulus and the Poisson's ratio $v$ determined by a dynamic technique. The static elastic modulus of the mortar was measured on three (or two for the silica fume system) mortar prisms $\left(40 \times 40 \times 160 \mathrm{~mm}^{3}\right)$ for each mixture in accordance with EN 196-1. The samples were equipped with two extensometers that monitored the displacement while loaded up to $30 \%$ of the compressive strength. The Poisson's ratio was determined by resonant ultrasound spectroscopy (RUS) on two samples or on one sample (for the silica fume system). In this method, the vibration eigenmodes are excited over a certain frequency range and the correspondent eigenfrequencies are measured. Finally, the eigenfrequencies are used to calculate the elastic properties knowing density and geometry [59-61]. Table 3 shows the bulk moduli used as input for modeling.

Estimating the error of the static elastic modulus or Poisson ratio can be done in a straightforward way by using the standard deviation obtained from the measurements performed on replicate samples. For the bulk modulus, being a function of the parameters determined experimentally using for each a different 
Table 3 Bulk modulus calculated from static elastic modulus and dynamically-determined Poisson's ratio

\begin{tabular}{lccc}
\hline & OPC & Slag & Silica fume \\
\hline Static elastic modulus $E(\mathrm{GPa})$ & $26.7 \pm 1.2$ & $25.9 \pm 0.7$ & $25.4 \pm 0.6$ \\
Dynamic Poisson's ratio, $v$ & $0.199 \pm 0.024$ & $0.231 \pm 0.006$ & $0.181 \pm 0.007$ \\
Bulk modulus $K_{\mathrm{b}}(\mathrm{GPa})^{*}$ & $14.8 \pm 0.9$ & $16.0 \pm 0.4$ & $13.3 \pm 0.3$ \\
Water-accessible porosity, $50{ }^{\circ} \mathrm{C}(\%)$ & $14.0 \pm 0.7$ & $14.0 \pm 0.8$ & $18.0 \pm 0.7$ \\
Water-accessible porosity, $105^{\circ} \mathrm{C}(\%)$ & $21.0 \pm 0.1$ & $22.0 \pm 0.8$ & $26.0 \pm 0.1$ \\
\hline
\end{tabular}

The water-accessible porosity was measured by referencing the initial saturated sample mass to the dry mass after oven storage at $50{ }^{\circ} \mathrm{C}$ and at $105{ }^{\circ} \mathrm{C}$. Errors estimates refer to standard deviation obtained from the replicate measurements or with a parametric bootstrapping technique (for bulk modulus)

* Estimated based on parametric bootstrapping

method, the propagation of uncertainty was obtained by means of parametric bootstrapping, similarly as described in Sect. 2.3.

While the bulk modulus of the porous solid $K_{\mathrm{b}}$ can be calculated from the elastic modulus $E$ and the Poisson's ratio, the determination of the bulk moduli of the skeleton $K_{\mathrm{s}}$ is not trivial. The latter depends on the bulk moduli of all the solid phases forming the mortar. The main problem derives from the determination of $K_{\mathrm{s}}$ for the intrinsically-porous CSH. Grasley et al. experimentally quantified the $K_{\mathrm{s}}$ of cement paste and concrete at early-age [53]. Results ranged between 40 and $55 \mathrm{GPa}$. Further, they also suggested that the $K_{\mathrm{s}}$ of mature concretes is expected to be in the same range as the one of the aggregates, since cement particles (with high $K_{\mathrm{s}}$ ) are converted to less stiff hydration products. In this study, the bulk modulus of the solids was assumed to be $38 \mathrm{GPa}$. This value was chosen using the effective medium approach by Hashin and Shtrikman [62] and considering that $50 \%$ of the mortar is occupied by sand and $50 \%$ by cement paste.

\section{Drying shrinkage: comparison of experiments and simulations}

\subsection{Experimental results}

Figure 3 shows the measured shrinkage strains at moisture equilibrium of the three mortar mixtures as a function of the $\mathrm{RH}$. The shrinkage results were calculated as average of three specimens. The error bars represent the standard deviation of the three measured samples.

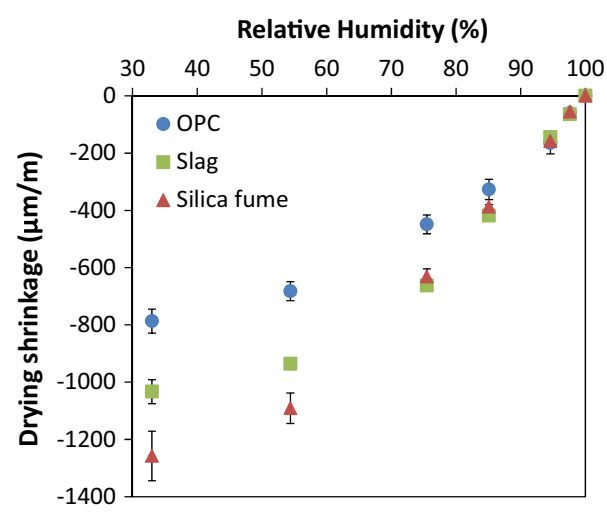

Fig. 3 Ultimate drying shrinkage as a function of RH. Error bars represent standard deviation of three samples

The mortars containing SCM show systematically higher shrinkage than the OPC mortar especially at RH levels below $85 \%$. Until $75 \%$ RH, no substantial differences are observed between mortars with slag or silica fume. At lower RH levels, however, the ultimate shrinkage of the silica fume mortar is higher than for the slag mortar.

It should be noted that the experimental results shown in Fig. 3 (and later in Figs. 4, 5, 6) refer to the first drying branch, with the saturated state as a reference point, similarly as in $[38,63]$. This is at odds with some previous studies, e.g. [23], where the sample had been initially dried before the shrinkage measurements took place. The reason for neglecting the first shrinkage branch and analyzing only the second and subsequent drying cycles in the discussion of shrinkage mechanisms was to avoid the irreversibility (and hence-the postulated non-elasticity) of shrinkage observed in the first adsorption that 

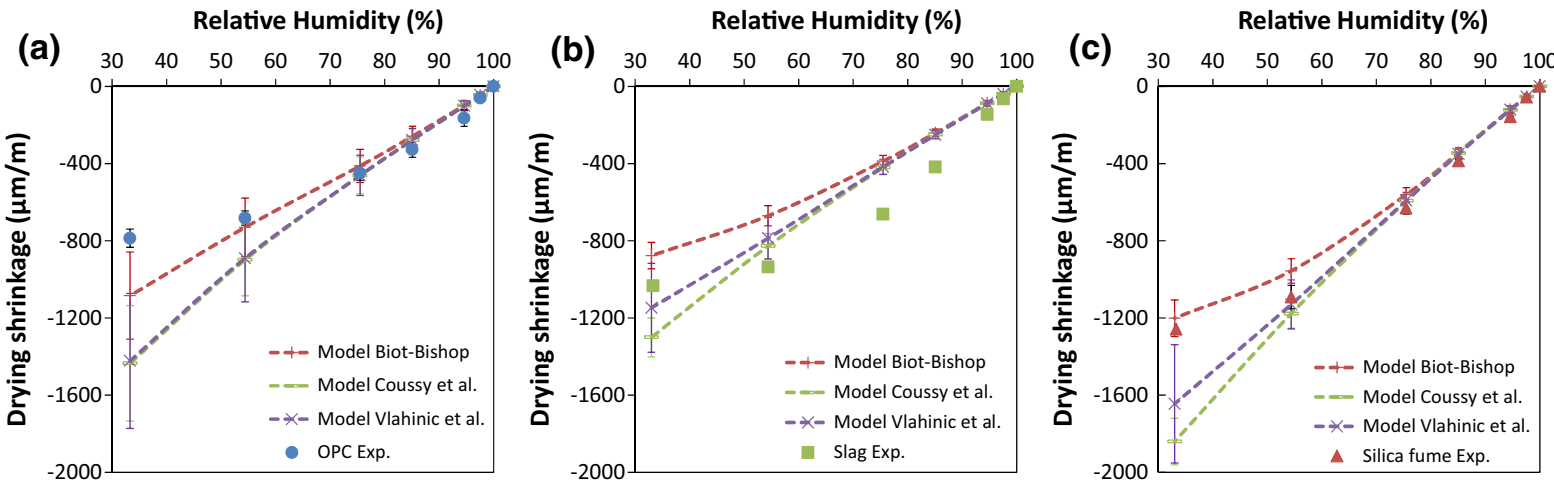

Fig. 4 Comparison of the predicted values by the three different formulations with the experimental results obtained for the three mortars: a OPC, $\mathbf{b}$ slag and $\mathbf{c}$ silica fume. Error bars represent $95 \%$ CI (obtained from bootstrapping in the case of predictions and from normal distributions in the case of experimental data). The saturation degree used in the model was obtained by referencing to dry mass at $105^{\circ} \mathrm{C}$
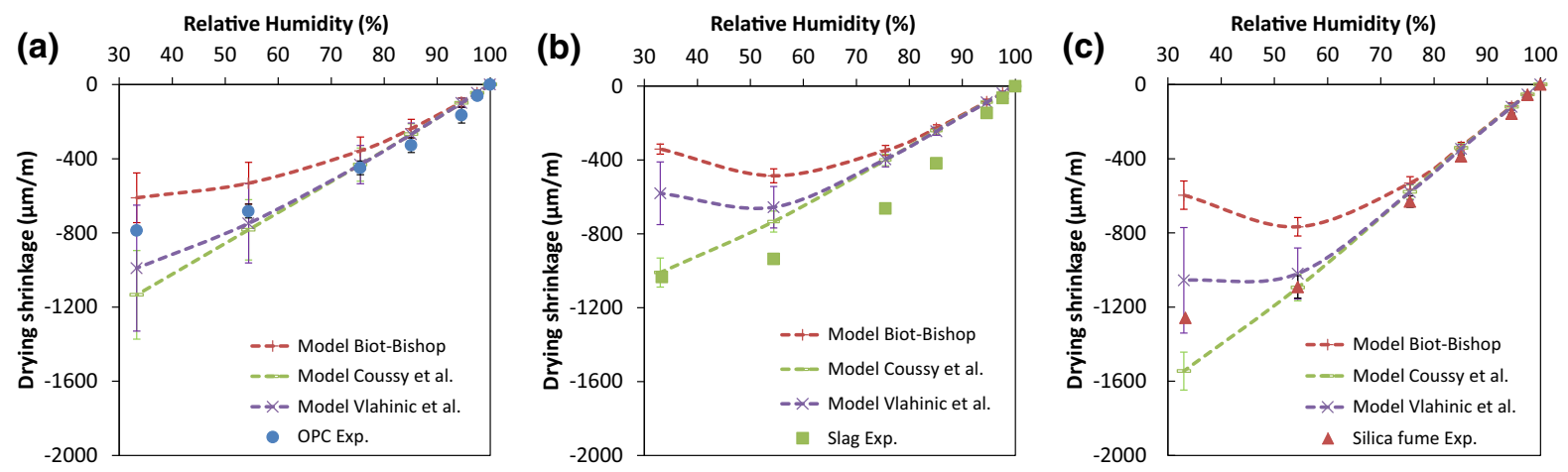

Fig. 5 Comparison of the predicted values by the three different formulations with the experimental results (see caption of Fig. 4). The saturation degree used in the model was obtained by referencing to a dry mass at $50{ }^{\circ} \mathrm{C}$

(a) Relative Humidity (\%)

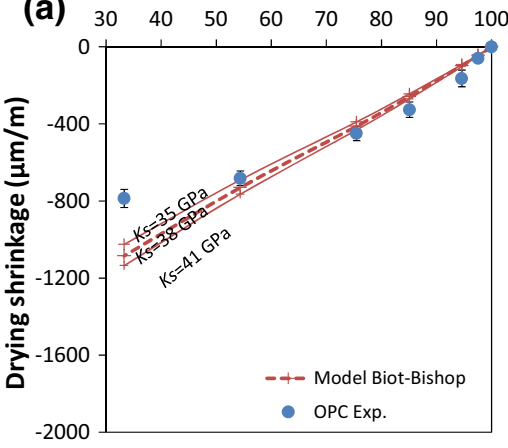

Relative Humidity (\%)

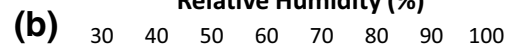

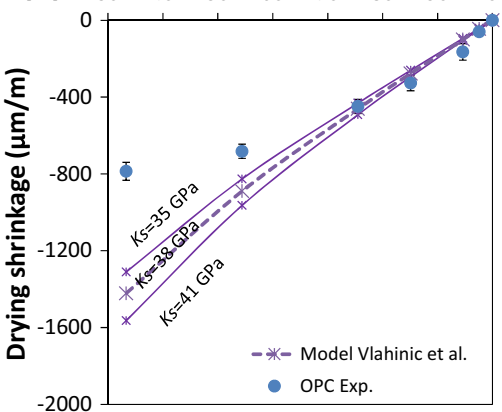

(c) Relative Humidity (\%)

(c) $\begin{array}{llllllll}30 & 40 & 50 & 60 & 70 & 80 & 90 & 100\end{array}$

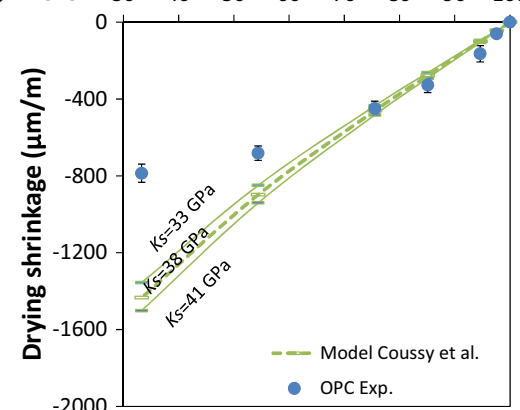

Fig. 6 The effect of the assumed bulk modulus of the solid skeleton (studied only for the OPC mortar) $K_{\mathrm{s}}=38 \mathrm{GPa}$ (as in Fig. 4 ), $K_{\mathrm{s}}=35 \mathrm{GPa}$ and $K_{\mathrm{s}}=41 \mathrm{GPa}$ in the three different models: a Biot-Bishop, b Coussy et al., c Vlahinić et al

followed the initial first desorption [23]. We do not support this approach and note that, when the possible influence of irreversible phenomena is eliminated, shrinkage occurring in the first drying cycle can be in fact explained based on poroelastic theory. As possible non-elastic phenomena that may lead to irreversible 
shrinkage, one can name microcracking and carbonation shrinkage. The former was avoided by an extremely slow drying process (step-wise drying) of the miniature samples in order to minimize the moisture gradients and therefore the buildup of stresses due to self-restraint. The latter was avoided by drying the samples in nitrogen atmosphere. The same approach was also applied in the works by Setzer [38] and Maruyama et al. [63]. Their results clearly show that the irreversibility of shrinkage observed upon resaturation (manifested in the fact that the absolute shrinkage, referred to the virgin saturated state, is higher on adsorption than on the preceding desorption) is in fact due to the well-known hysteresis of the sorption isotherm [38]. In other words, the hysteresis (irreversibility) in shrinkage stems directly from the different water content equilibrium states on desorption/adsorption, and it becomes negligible when shrinkage is plotted as a function of water content, as evidenced in [38, 63]. Following this observation, it can be concluded that drying shrinkage of cementitious materials in the first drying cycle can be explained with the poroelastic approaches investigated in this paper. Moreover, it would be also possible to apply this approach to explain hysteresis of drying shrinkage, as its effect is accounted for by means of the saturation degree used as input parameter.

\subsection{Drying shrinkage prediction vs experimental shrinkage}

The modelling results according to (1) the Biot-Bishop model, (2) the Coussy et al. model and (3) the Vlahinić et al. model are presented and compared with the experimental data in Figs. 4 and 5, for the two sets of saturation degree data, determined by referencing to dry mass at 105 and $50{ }^{\circ} \mathrm{C}$, respectively. The bootstrapped $95 \% \mathrm{CI}$ are also presented in Figs. 4 and 5. Regarding propagation of uncertainty, it can be noted that the confidence intervals increase at decreasing RH, which for an approximately constant variability of the input parameters is due to the scaling effect of the pressure (because the pore pressure increases exponentially with a $\mathrm{RH}$ decrease, see Eq. 1). It was found that more than half of the width of the confidence interval is due to the variability of the experimentally-determined Poisson ratio. The width of the confidence band resulting from propagation of uncertainty of the experimental data is relatively narrow (below $\pm 100 \mu \mathrm{m} / \mathrm{m}$ ) for $\mathrm{RH}$ above about $75 \% \mathrm{RH}$. It should be reminded that this regards only the error of the determined parameters according to a certain assumed method, and does not include the effect of different possible assumptions, like the effect of saturation degree or bulk modulus of solid skeleton discussed further.

It can be seen that, except for the slag mortar, all three models are capable of predicting the shrinkage with good accuracy for RH above $54 \%$, and especially above $75 \%$. It should be noted, that equilibrium RH below about $50 \%$ will not be reached in most of engineering structures around the world. In this RH range the difference between the saturation degrees determined using two different temperatures as reference is of minor importance, compare Figs. 4 and 5. For the Slag mortar, all three models underestimated the high shrinkage observed experimentally.

The differences between the three models and their sensitivity to the determined saturation degree start to be significant at RH below about $54 \%$ RH. With both sets of saturation degree data, the additional term considered in the Coussy et al. model due to interfacial phenomena (see Eq. (4)) leads to an approximately constant slope of the strain-RH curve along the whole range of analyzed RH. This is not in agreement with the experimental data presented in Fig. 3 and other published experimental data $[38,64]$, where a bi-linear character of the strain-RH curve was observed, with a decrease of slope around 40-50\% RH. On the other hand, using the Biot-Bishop model or Vlahinić et al. model one can account for the change in slope in the curves. Of these two models, for RH below about 54 $\%$, the Biot-Bishop model provided better agreement with experimental data when the saturation degree was obtained by referencing to dry mass at $105{ }^{\circ} \mathrm{C}$, see Fig. 4, while the Vlahinić et al. model agreed better for the saturation degree obtained by referencing to dry mass at $50{ }^{\circ} \mathrm{C}$.

This leads to observe that the assumptions in the determination of the saturation degree have a key influence on the model predictions. Indeed, in all three models, this parameter directly governs the driving force of shrinkage (Eqs. 3, 5, 6) and in the Vlahinić et al. model it additionally controls the poroelastic response (Eq. 7). The porosity used as an input parameter in the latter model is also prone to the 
effect of different reference state; it is however of negligible importance compared to saturation degree.

As underlined by Hansen [65], evaporable water in cement-based system (and therefore the determined saturation degree or porosity) is a relative term dependent upon the method of drying used. Using oven drying at around $100{ }^{\circ} \mathrm{C}$ is a commonly-applied method for determination of the reference dry mass in cementitious materials. It was reported in [65] that oven drying at around $105{ }^{\circ} \mathrm{C}$ allows to remove approximately the same water amount as drying at vapor pressure of 0.007 bar at $25^{\circ} \mathrm{C}$. At the same time, as reported by Zhang and Scherer [66], determination of dry mass at $105^{\circ} \mathrm{C}$ may be prone to an error due to decomposition of part of hydration products (in particular ettringite and $\mathrm{CSH}$ ) at this temperature. This would lead to an overestimation of the determined saturation degree.

On the other hand, lower drying temperatures may not allow to remove all free water from the samples. The hypothesis of insufficient drying at $50{ }^{\circ} \mathrm{C}$ for the tested sample is confirmed by the very low porosity determined when using dry mass at $50{ }^{\circ} \mathrm{C}$, see Table 3 . The predicted drop of shrinkage observed for the BiotBishop and also Vlahinić et al. models for slag and silica fume mortars at $33 \% \mathrm{RH}$ (Fig. 5), is due to very low degrees of saturation determined for these mortars when referenced to dry mass at $50{ }^{\circ} \mathrm{C}$, and may be another indication that using this temperature lead to an underestimation of the actual saturation degree.

Another parameter of which determination is not straightforward is $K_{s}$; in the simulations this parameter was assumed as constant (as defined in the previous sections). In order to estimate the influence of this parameter on the predicted shrinkage strains, in lack of direct experimental data regarding its variability, a simple estimation was performed. The originally assumed $K_{\mathrm{s}}$ value (38 $\mathrm{GPa}$ ) was varied in the range of $\pm 3 \mathrm{GPa}$; the results are presented in Fig. 6 for the OPC mortar and the dataset with saturation degree obtained at $105^{\circ} \mathrm{C}$. From such estimation it is deduced that the parameter $K_{\mathrm{s}}$ is of secondary importance at the RH levels considered. In addition, it should be noted that higher $K_{\mathrm{s}}$ values would consistently have a smaller influence on the shrinkage predictions.

In previous studies, the Biot-Bishop model has been shown to substantially underestimate the shrinkage predictions of cement pastes [23-25, 27, 28]. On the contrary, our results show, that, considering the discussed uncertainty of the saturation degree, the Biot-Bishop model can describe reasonably well the experimental data on mortars, especially when the saturation degree is determined by drying at $105^{\circ} \mathrm{C}$, both regarding the trend and the magnitude of shrinkage. This satisfactory performance of the BiotBishop model may be due to the fact that the experimental conditions in the present study allowed to reduce to a minimum the irreversible, non-elastic shrinkage component. This concerns e.g. avoiding carbonation shrinkage, that may have been occurred in other published results, e.g. [23]. Furthermore, viscoelastic effect may lead to underestimate the shrinkage when using a poroelastic approach, as shown in [28]. Unlike for the cement pastes tested in e.g. $[23,28]$, for the mortars presented here, the macroscopic manifestation of viscoelastic behavior, i.e. creep deformation contributing to the measured shrinkage, may have been limited due to the restraining action of the aggregates.

\section{Conclusions}

In this paper, the ultimate drying shrinkage as a function of the equilibrium $\mathrm{RH}$ of three cement-based mortars was investigated, namely the OPC mortar and two mortars where a portion of the cement was replaced by slag or silica fume.

The measured ultimate drying shrinkage was compared to the predicted shrinkage obtained through mechanistic models. Specifically, three different modeling approaches based on poroelasticity were employed to describe the ultimate shrinkage of unsaturated mortars and their predictive ability evaluated. Further, the propagation of the uncertainty was also addressed by means of parametric bootstrapping.

Mortar mixtures including SCM showed a systematic increase of the ultimate shrinkage as a function of the RH in comparison to the OPC mortar. At RH levels below $75 \%$, the silica fume mortar showed the highest shrinkage.

Comparison of the experimental ultimate shrinkage results with the predictions obtained by the three model formulations for unsaturated media showed that all three models were able to predict the ultimate shrinkage-RH trends with good accuracy for RH above about $54 \%$ RH. For lower RH, the Biot-Bishop model and Vlahinić et al. model allowed to predict the 
bi-linear character of the shrinkage-RH curves, with change of slope around $50 \% \mathrm{RH}$. This is in agreement also with the previously published literature data. On the contrary, the Coussy et al. model results in approximately constant shrinkage-RH slope.

It was found that one of the most crucial parameters in predicting of shrinkage is the saturation degree that is used in the poroelastic model as a parameter directly governing the driving force, i.e. changes in pore pressure. This parameter depends on the assumed reference method for determination of free water content. The effects of two different oven drying temperatures, 105 and $50{ }^{\circ} \mathrm{C}$ on the predicted shrinkage were used to highlight the importance of this parameter.

The agreement between the predicted and observed shrinkage, especially for the Biot-Bishop model and Vlahinić et al. model, was good for the OPC and silica fume mortar. For the slag mortar mixtures, all applied models underestimated the very high shrinkage observed experimentally at RH already above $54 \%$ $\mathrm{RH}$. The results in general suggest that the shrinkage of mortars can be described using poroelastic approaches as long as possible non-elastic phenomena are avoided, in particular when the material is protected from carbonation and microcracking.

Acknowledgments We would like to thank Prof. Zachary Grasley for the inspiring discussion on the bulk modulus of solid skeleton and poroelasticity. This project was financed by the Nanocem consortium (Core Project 13, Early-Age Shrinkage and Cracking of Cementitious Materials).

\section{References}

1. Bisschop J, Van Mier J (2002) Effect of aggregates on drying shrinkage microcracking in cement-based composites. Mater Struct 35(8):453-461

2. Weiss WJ, Yang W, Shah SP (1998) Shrinkage cracking of restrained concrete slabs. J Eng Mech 124(7):765-774

3. Ytterberg R (1987) Shrinkage and curling of slabs on grade (Part a). Concr Int 9(4):22-31

4. Bissonnette B, Attiogbe EK, Miltenberger MA, Fortin C (2007) Drying shrinkage, curling, and joint opening of slabs-on-ground. ACI Mater J 104(3):259

5. ACI-209 (2008) Guide for modeling and calculating shrinkage and creep in hardened concrete. Farmington Hills, American Concrete Institute, p 48

6. EN-1992-1-1 (2008) Eurocode 2-design of concrete structures. Comite Europeen de Normalisation (CEN), Brussels, p 259
7. Bažant ZP, Baweja S (1995) Justification and refinements of model B3 for concrete creep and shrinkage 1. Statistics and sensitivity. Mater Struct 28(7):415-430

8. CEB-FIP (1990) Model code for concrete structures. Comite Euro-International du Beton, p 462

9. Gardner N, Lockman M (2001) Design provisions for drying shrinkage and creep of normal-strength concrete. ACI Mater J 98(2): 159

10. Bažant ZP (2001) Prediction of concrete creep and shrinkage: past, present and future. Nucl Eng Des 203(1):27-38

11. Almudaiheem $\mathbf{J}$ (1992) An improved model to predict the ultimate drying shrinkage of concrete. Mag Concr Res 44(159):81-85

12. Bazant ZP, Chern J-C (1984) Bayesian statistical prediction of concrete creep and shrinkage. In: ACI journal proceedings, ACI

13. Al-Manaseer A, Lam J-P (2005) Statistical evaluation of shrinkage and creep models. ACI Mater J 102(3):170

14. Theiner Y, Andreatta A, Hofstetter G (2014) Evaluation of models for estimating concrete strains due to drying shrinkage. Struct Concr 15(4):461-468

15. Jonasson J-E (2009) A study of time-dependent deformations in modern concrete. Creep, shrinkage and durability of concrete and concrete structures. In: Proceedings of the eight international conference on Creep, Shrinkage and Durability of Concrete and Concrete Structures, Ise-Shima, Japan, 30 Sept-2 Oct 2008. CRC Press, Boca Raton

16. Wendner R, Hubler M, Bazant Z (2013) The B4 model for multi-decade creep and shrinkage prediction. In: Proceedings of the ninth international conference on creep, shrinkage, and durability mechanics (Concreep-9), pp 429-436

17. Bazant Z, Hubler M, Wendner R (2014) Model B4 for creep, drying shrinkage and autogenous shrinkage of normal and high-strength concretes with multi-decade applicability. TC-242-MDC multi-decade creep and shrinkage of concrete: material model and structural analysis. RILEM Mater Struct

18. Pickett G (1956) Effect of aggregate on shrinkage of concrete and a hypothesis concerning shrinkage. In: ACI journal proceedings. ACI

19. Hansen TC, Nielsen KE (1965) Influence of aggregate properties on concrete shrinkage. In: ACI journal proceedings. ACI

20. Coussy O (2005) Poromechanics. Wiley, Chichester

21. Coussy O, Eymard R, Lassabatere T (1998) Constitutive modeling of unsaturated drying deformable materials. J Eng Mech 124(6):658-667

22. Baroghel-Bouny V, Mainguy M, Lassabatere T, Coussy O (1999) Characterization and identification of equilibrium and transfer moisture properties for ordinary and high-performance cementitious materials. Cem Concr Res 29(8):1225-1238

23. Vlahinić I, Jennings HM, Thomas JJ (2009) A constitutive model for drying of a partially saturated porous material. Mech Mater 41(3):319-328

24. Rougelot T, Skoczylas F, Burlion N (2009) Water desorption and shrinkage in mortars and cement pastes: experimental study and poromechanical model. Cem Concr Res 39(1):36-44

25. Bentz DP, Garboczi EJ, Quenard DA (1998) Modelling drying shrinkage in reconstructed porous materials: 
application to porous Vycor glass. Model Simul Mater Sci Eng 6(3):211

26. Mackenzie J (1950) The elastic constants of a solid containing spherical holes. Proc Phys Soc Lond Sect B 63(1):2

27. Lura P, Jensen OM, van Breugel K (2003) Autogenous shrinkage in high-performance cement paste: an evaluation of basic mechanisms. Cem Concr Res 33(2):223-232

28. Grasley ZC, Leung CK (2011) Desiccation shrinkage of cementitious materials as an aging, poroviscoelastic response. Cem Concr Res 41(1):77-89

29. Biot MA (1941) General theory of three-dimensional consolidation. J Appl Phys 12(2):155-164

30. Bishop A (1959) The effective stress principle. Teknisk Ukeblad 39:859-863

31. Kass RE, Eden UT, Brown EN (2014) Propagation of uncertainty and the bootstrap. Analysis of neural data. Springer, New York, pp 221-246

32. Wittmann F (1973) Interaction of hardened cement paste and water. J Am Ceram Soc 56(8):409-415

33. Hansen W (1987) Drying shrinkage mechanisms in Portland cement paste. J Am Ceram Soc 70(5):323-328

34. Roper H (1966) Dimensional change and water sorption studies of cement paste. Highway Research Board Special Report, vol 1966, No 90

35. Derjaguin BV (1987) Some results from 50 years' research on surface forces. Springer, New York

36. Duckheim C, Setzer M (2008) Drying shrinkage mechanisms of hardened cement paste. Proc Creep Shrinkage Durab Mech Concr Concr Struct 2008:49-55

37. Ferraris C, Wittmann FH (1987) Shrinkage mechanisms of hardened cement paste. Cem Concr Res 17(3):453-464

38. Setzer MJ, Duckheim C, Liebrecht A, Kruschwitz J (2008) The solid-liquid gel-system of hardened cement paste. Proc Concreep 8:237-243

39. Neville AM (1995) Properties of concrete. Prentice Hall, Englewood Cliffs

40. Chen H, Wyrzykowski M, Scrivener K, Lura P (2013) Prediction of self-desiccation in low water-to-cement ratio pastes based on pore structure evolution. Cem Concr Res 49:38-47

41. Mindess S, Young JF, Darwin D (2003) Concrete. Prentice Hall, Englewood Cliffs

42. Andrade C, Sarría J, Alonso C (1999) Relative humidity in the interior of concrete exposed to natural and artificial weathering. Cem Concr Res 29(8):1249-1259

43. Biot MA (1955) Theory of elasticity and consolidation for a porous anisotropic solid. J Appl Phys 26(2):182-185

44. Biot M, Willis D (1957) The theory of consolidation. J Appl Elast Coeff Mech 24:594-601

45. Skempton A (1984) Effective stress in soils, concrete and rocks. Selected papers on soil mechanics vol 1032, pp 4-16

46. Bishop AW, Blight G (1963) Some aspects of effective stress in saturated and partly saturated soils. Geotechnique 13(3): 177-197

47. Scherer G (2004) Characterization of saturated porous bodies. Mater Struct 37(1):21-30

48. Hutter K, Laloui L, Vulliet L (1999) Thermodynamically based mixture models of saturated and unsaturated soils. Mech Cohesive-Frictional Mater 4(4):295-338
49. Lewis RW, Schrefler BA (1987) The finite element method in the deformation and consolidation of porous media. Wiley, Chichester

50. Coussy O, Dangla P, Lassabatère T, Baroghel-Bouny V (2004) The equivalent pore pressure and the swelling and shrinkage of cement-based materials. Mater Struct 37(1):15-20

51. Chernick MR (2011) Bootstrap methods: a guide for practitioners and researchers. Wiley, Hoboken

52. Greenspan L (1977) Humidity fixed points of binary saturated aqueous solutions. J Res Natl Bur Stand 81(1):89-96

53. Grasley ZC, Scherer GW, Lange DA, Valenza JJ (2007) Dynamic pressurization method for measuring permeability and modulus: II. Cementitious materials. Mater Struct 40(7):711-721

54. Termkhajornkit P, Barbarulo R, Chanvillard G (2015) Microstructurally-designed cement pastes: a mimic strategy to determine the relationships between microstructure and properties at any hydration degree. Cem Concr Res 71:66-77

55. Di Bella C, Wyrzykowsky M, Griffa M, Termkhajonkit P, Chanvillard G, Stang H, et al (2015) Application of microstructurally-designed mortars for studying early-age properties: microstructure and mechanical properties. Submitted CCR

56. Bisschop J (2002) Drying shrinkage microcracking in cement-based materials. TU Delft, Delft University of Technology, Delft

57. Villani C, Spragg R, Pour-Ghaz M, Jason Weiss W (2014) The influence of pore solutions properties on drying in cementitious materials. J Am Ceram Soc 97(2):386-393

58. Espinosa RM, Franke L (2006) Influence of the age and drying process on pore structure and sorption isotherms of hardened cement paste. Cem Concr Res 36(10):1969-1984

59. Migliori A, Darling TW (1996) Resonant ultrasound spectroscopy for materials studies and non-destructive testing. Ultrasonics 34(2):473-476

60. Wu W, Al-Ostaz A, Gladden J, Cheng A, Li G (2010) Measurement of mechanical properties of hydrated cement paste using resonant ultrasound spectroscopy. J ASTM Int 7(5): $1-8$

61. ASTM Standard C215-08 (2008) Standard test method for fundamental transverse, longitudinal, and torsional resonant frequencies of concrete specimens. ASTM International

62. Hashin Z, Shtrikman S (1963) A variational approach to the theory of the elastic behaviour of multiphase materials. J Mech Phys Solids 11(2):127-140

63. Maruyama I (2010) Origin of drying shrinkage of hardened cement paste: hydration pressure. J Adv Concr Technol 8(2):187-200

64. Weiss J, Lura P, Rajabipour F, Sant G (2008) Performance of shrinkage-reducing admixtures at different humidities and at early ages. ACI Mater J 105(5):478-486

65. Hansen T (1986) Physical structure of hardened cement paste. A classical approach. Mater Struct 19(6):423-436

66. Zhang J, Scherer GW (2011) Comparison of methods for arresting hydration of cement. Cem Concr Res 41(10):1024-1036 